\title{
Additive Techniques to Refurbish Ni Based Components
}

\author{
Eloisa Pereira Cardozo ${ }^{1}$ (D), Gonçalo Rodrigues Pardal² (D), Sergio Ríos ${ }^{3}$ (D), Supriyo Ganguly² (D), Ana Sofia C. M. D’Oliveira ${ }^{1}$ (D) \\ ${ }^{1}$ Universidade Federal do Paraná - UFPR, Departamento de Engenharia Mecânica, Setor de Tecnologia, Curitiba, PR, Brasil. \\ ${ }^{2}$ Cranfield University, School of Aerospace/Transport and Manufacturing, Cranfield, United Kingdom. \\ ${ }^{3}$ University of Magallanes, Chile
}

How to cite: Cardozo EP, Pardal GR, Ríos S, Ganguly S, D'Oliveira ASCM. Additive techniques to refurbish Ni based components. Soldagem \& Inspeção. 2019;24:e2403. https://doi.org/10.1590/0104-9224/SI24.03

\begin{abstract}
The attractiveness of additive techniques to refurbish worn components requires the availability of data from different process. This study correlates two additive techniques, Plasma Transferred Arc (PTA - AM) and Direct Laser Deposition (DLD), using IN 625 wire. Specific features of each technique are discussed regarding their potential use to recover geometry and properties of worn components. Multilayers were processed with each technique on a section of a blade and the interaction between materials together with the effect of post deposition heat treatment were characterized. Results show that there are differences in the final microstructure and in the interaction with the part being refurbished imposed by the additive technique used. Competitive changes can be made by changing the feedstock. PTA-AM using powder material exhibits a microstructure that approaches that obtained in DLD using wire.
\end{abstract}

Key-words: Additive manufacturing; Direct laser deposition; PTA, Inconel 625; Refurbishing.

\section{Introduction}

Additive manufacturing ( $A M)$ is a technology by which a part is build, layer by layer, from a 3D model. It arrives at the current industrial scenario as a fast, versatile, flexible, and a competitive production path compared with conventional manufacturing particularly when working with components of high geometric complexity. Several challenges are associated with Additive Manufacturing for the coming years and at the top of the list there is a need to better understand the link between materials, process and properties of additive parts [1]. For this purpose sufficient data needs to be available in order to create a database allowing to acquire sounds relationships that can better support industries worldwide.

A range of processing technologies are being used for additive components, including hybrid machines that can finish a component immediately after multilayer processing. Regarding AM techniques, a classification can be made according to the energy available to melt the feedstock. Some additive techniques can build and refurbish components, although the later requires the interaction with the component being refurbished to be accounted for. When selecting an additive technique one is faced with a lack of studies allowing direct comparison between techniques, nevertheless typical features associated with each technique can be identified. Direct Laser Deposition (DLD) processes can use feeding rates ranging from 0,1 to $1 \mathrm{~g} / \mathrm{s}$ while the feeding rate in arc deposition processes can reach up to $2,8 \mathrm{~g} / \mathrm{s}$ [2]. The Plasma Transferred Arc (PTA) process fits in the later and represents a competitive alternative for AM production (PTA-AM) allowing high feeding rate and low heat input [3]. Furthermore, it offers good homogeneity of the deposits and low oxides content being recommended both for building and repairing. However, when using the PTA-AM process the number of parameters that need to be defined and optimized for each operating condition can make it complex. These parameters are: main arc current, pilot arc current, voltage, powder or wire feed rate, feed gas flow, shield gas flow, plasma gas flow, electrode set back, stand-out distance, etc. The control of all these parameters, added to the characteristics of the feedstock and the history of the parts to be refurbished directly influence the properties and the microstructure of multilayers [3]. Sames et al. [4] highlight that interactions between the heat source and the feedstock or melt pool may impact the energy efficiency. In laser processes, for example, there may be loss of intensity due to beam reflection, which must be compensated during processing.

When assessing PTA-AM, a lower energy density process compared to DLD, thermal and mechanical effects have to be considered during deposition. Reis et al. [5] points out that the thermal effect is related to the thermal coupling of the electric arc with the material and the enthalpy of ionization of the gases. From the thermal point of view, what is expected is that the more intense the heat reaching the part, the greater the molten volume. The heat is proportional to the current intensity and inversely proportional to the welding speed. Mechanical effect can be accounted for by two mechanisms: the impact of the plasma jet on the liquid metal and the mechanical action of magnetic fields created by the current driven by the arc. Therefore, it can be expected that higher plasma gas flow rates will promote higher mechanical action on the melt pool, as it does increasing current. In contrast, the build of deposits with DLD depends mainly on the power density and material where the beam will be

Recebido: 18 Set., 2018. Aceito: 22 Fev., 2019.

E-mail: eloisa.cardozo@ufpr.br (EPC)

This is an Open Access article distributed under the terms of the Creative Commons Attribution Non-Commercial License which permits unrestricted noncommercial use, distribution, and reproduction in any medium provided the original work is properly cited. 
focused. These different processing mechanisms impose that different set of parameters have to be selected to promote the best quality deposits from each technique.

Besides the process, the material to be deposited plays an important role on the quality and properties of the part being refurbished. Inconel 625 alloy (IN 625), a nickel-based superalloy with good weldability, is used to refurbish Ni based parts. It is mainly hardened by the solid solution hardening effect of niobium and molybdenum elements in a nickel and chromium matrix [6]. Although originally developed as a solid solution hardened alloy, it also offers the possibility of hardening by the effect of the $\gamma$ " phase (Ni3Nb) precipitation, fine and metastable, after aging for a long period at temperature ranging from $550{ }^{\circ} \mathrm{C}$ to $850{ }^{\circ} \mathrm{C}$ [7]. In 625 alloy is widely used in aeronautic, aerospace, chemical and petrochemical industries and is known for its excellent combination of tensile strength, toughness, good fabricability, weldability and resistance to oxidation and corrosion at high temperatures even when exposed to aggressive environments during long periods [8].

Together with additive techniques, IN 625 alloy can result in effective refurbishing of components with functional geometries allowing performance improvement of worn components manufactured by conventional processes. In addition, it can be a suitable alloy to better understand the interaction between processing techniques and microstructure of the final component manufactured with additive techniques $[6,9,10]$. In this study a correlation between PTA-AM and DLD using IN 625 to refurbish a worn $\mathrm{Ni}$ based part aims at a better understanding of the features offered by each technique to support the most suitable process for additive maintenance.

\section{Materials and Methods}

Processing parameters were selected after preliminary tests for each additive technique aiming at simulating a refurbishing operation, as summarized in Table 1 and 2 for PTA-AM and DLD, respectively.

Table 1. Processing parameters used in PTA-AM deposition.

\begin{tabular}{cc} 
Feedstock & Inconel 625 wire \\
Diameter & $1,2 \mathrm{~mm}$ \\
Current & $115 \mathrm{~A}$ \\
Feeding Rate & $44 \mathrm{~mm} / \mathrm{s}(17,4 \mathrm{~g} / \mathrm{min})$ \\
Welding Speed & $6 \mathrm{~mm} / \mathrm{s}$ \\
Plasma Gas Flow Rate & $1 \mathrm{l} / \mathrm{min}$ \\
Shielding Gas Flow Rate & $10 \mathrm{l} / \mathrm{min}$ \\
Nozzle Orifice Diameter & $3,2 \mathrm{~mm}$ \\
Distance From Nozzle to Work Piece & $10 \mathrm{~mm}$ \\
Electrode Set Back & $1,9 \mathrm{~mm}$ \\
\hline
\end{tabular}

Table 2. Processing parameters used in direct Laser deposition.

\begin{tabular}{ccc}
\hline Feedstock & Inconel 625 wire \\
Diameter & Power & $1 \mathrm{~mm}$ \\
Beam angle & $1,5 \mathrm{~kW}$ \\
Feeding Rate & $10^{\circ}$ \\
Welding Speed & $30 \mathrm{~mm} / \mathrm{s}(6 \mathrm{~g} / \mathrm{min})$ \\
Feeding angle & $8,33 \mathrm{~mm} / \mathrm{s}$ \\
Nozzle Orifice Diameter & $35^{\circ}$ \\
\hline
\end{tabular}

Five IN 625 layers were deposited on a Renè 80 substrate $(30 \mathrm{~mm} \times 4 \mathrm{~mm} \times 600 \mathrm{~mm})$. The chemical composition of both materials used is shown on Table 3. 
Table 3. Chemical composition (\%wt) of in 625 and Renè 80 [11,12].

\begin{tabular}{|c|c|c|}
\hline & IN 625 & Renè 80 \\
\hline $\mathbf{N i}$ & Bal. & Bal. \\
\hline $\mathrm{Cr}$ & $20-23$ & 14 \\
\hline Co & 1 (Max.) & 9,5 \\
\hline Mo & $8-10$ & 4 \\
\hline $\mathbf{w}$ & - & 4 \\
\hline $\mathbf{N b}$ & $3,15-4,15$ & - \\
\hline Al & 0,4 (Max.) & 3 \\
\hline $\mathrm{Ti}$ & 0,4 (Max.) & 5 \\
\hline $\mathrm{Fe}$ & 5 (Max.) & - \\
\hline$M n$ & 0,5 (Max.) & - \\
\hline Si & 0,5 (Max.) & - \\
\hline C & 0,1 (Max.) & 0,17 \\
\hline B & - & 0,015 \\
\hline $\mathrm{Zr}$ & - & 0,03 \\
\hline
\end{tabular}

The multilayers were characterized both in the as deposited condition and after the post-deposition heat treatment (PDHT) applied in fabrication processes in order to homogenize microstructure and properties along the multilayer and also to stress relief. The PDHT was carried out in an argon atmosphere tubular furnace and included a three-step sequence with $1 \mathrm{~h}$ soaking at $1080^{\circ} \mathrm{C}$ for a time of $1 \mathrm{~h}$, followed by solubilization at $980^{\circ} \mathrm{C}$ for $1 \mathrm{~h}$ and aging at $720^{\circ} \mathrm{C}$ for $8 \mathrm{~h}$ [13].

Samples were prepared using standard metallographic procedures including grinding in silicon carbide paper and polishing with alumina. The phases were investigated by X-ray diffraction at the top surface of the multilayer parts. Cross-sectional micrographs of deposits were characterized by SEM (Scanning Electron Microscopy) and EDS (Energy Dispersive Spectroscopy) mapping. Vickers hardness profile at the cross-section used a $300 \mathrm{~g}$ load.

\section{Results and Discussions}

\subsection{As-processed multilayers}

The present study assessed the use of additive technologies to rebuild worn parts such as molds, turbine blades, etc. In contrast with the fabrication of new components the interaction with the part been refurbished is of significant importance. Planning the rebuilding of the geometry of a component and the recovering properties, requires a control of the multilayer deposition process in order to maintain control of the interaction between materials. As such the selected additive technology plays a determining role on the final result.

Analysis of multilayers processed with PTA-AM and DLD additive techniques revealed sound multilayers without cracking, lack of fusion or bonding along the multilayers or at the interface with the worn part. The higher values of feeding rate of the PTA process promoted thicker and higher multilayer structure with an effective area $(6,51 \times 3,41 \mathrm{~mm})$ significantly larger than the area offered by DLD $(5 \times 2,3 \mathrm{~mm})$.

The X-Ray Diffraction (XRD) spectrum at the top surface of multilayers, Figure 1, reveals that the phases formed during processing with PTA-AM and DLD are the same. However, it is interesting to note the apparent texture that forms when using PTA-AM as shown by the $\{220\}$ peaks. The higher cooling rate imposed by DLD process can account for the absence of the preferred orientation [14]. Further studies are required to better understand the solidification texture absent in the DLD multilayers particularly, since it reveals that intergranular stresses were generated during solidification and consequently phenomena like stress-corrosion cracking might occur. 


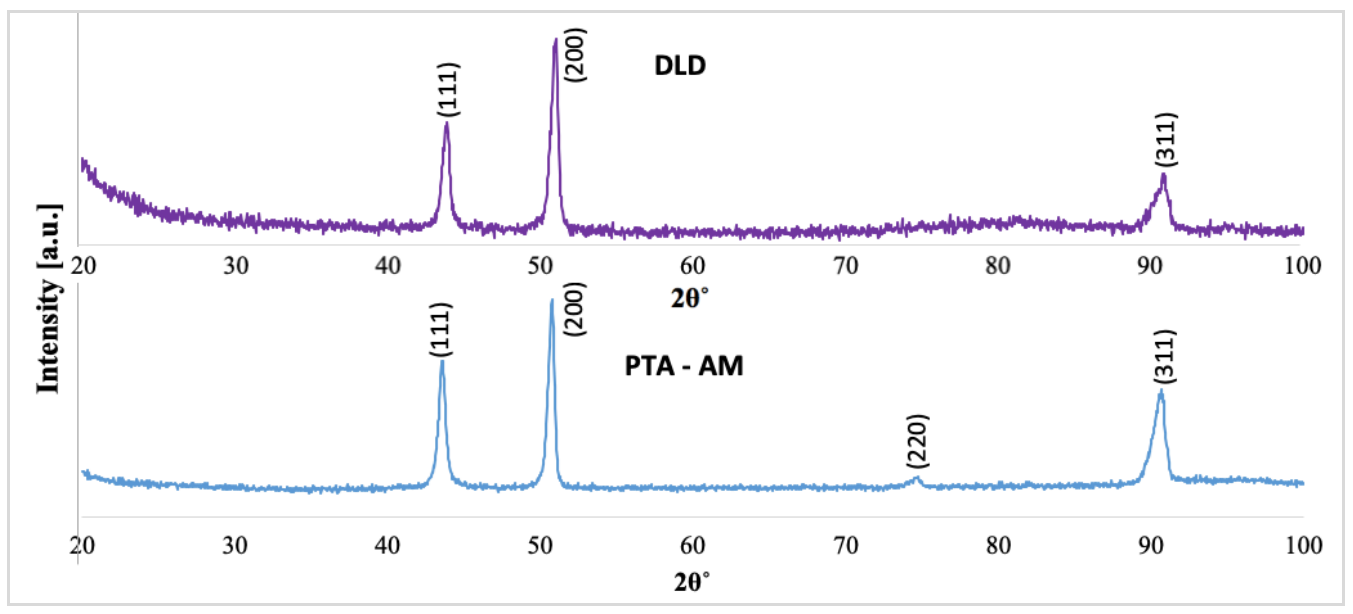

Figure 1. XRD from the top surface of the as-processed multilayers.

The effect of the two additive techniques on the refurbishing area can be identified in the hardness, Figure 2, and microstructure, Figure 3, particularly at the interface with the worn part, Figure 2(a). Hardness profiles along the center of the cross section of each multilayers, Figure 2 (c), include a minimum of 3 measurements in each region (center of the layer, interface between layers and substrate).

Regardless of the process used, the blade hardness increases towards the fusion line as a consequence of the thermal cycles that cause aging of the Renè 80 alloy, from the Heat Affected Zone to close to the deposited IN 625, Figure 2(a). It is of relevance to point out that, although very similar hardness was measured at the top layer $(317 \pm 30 \mathrm{HV}$ and $315 \pm 27 \mathrm{HV}$, for PTA$A M$ and DLD, respectively), Figure 2(b), the additive process influenced the region near the part being recovered. As shown in previous work [15] elements diffusing from the René 80 alloy substrate account for the increase in average hardness near the fusion line and in the first layer.

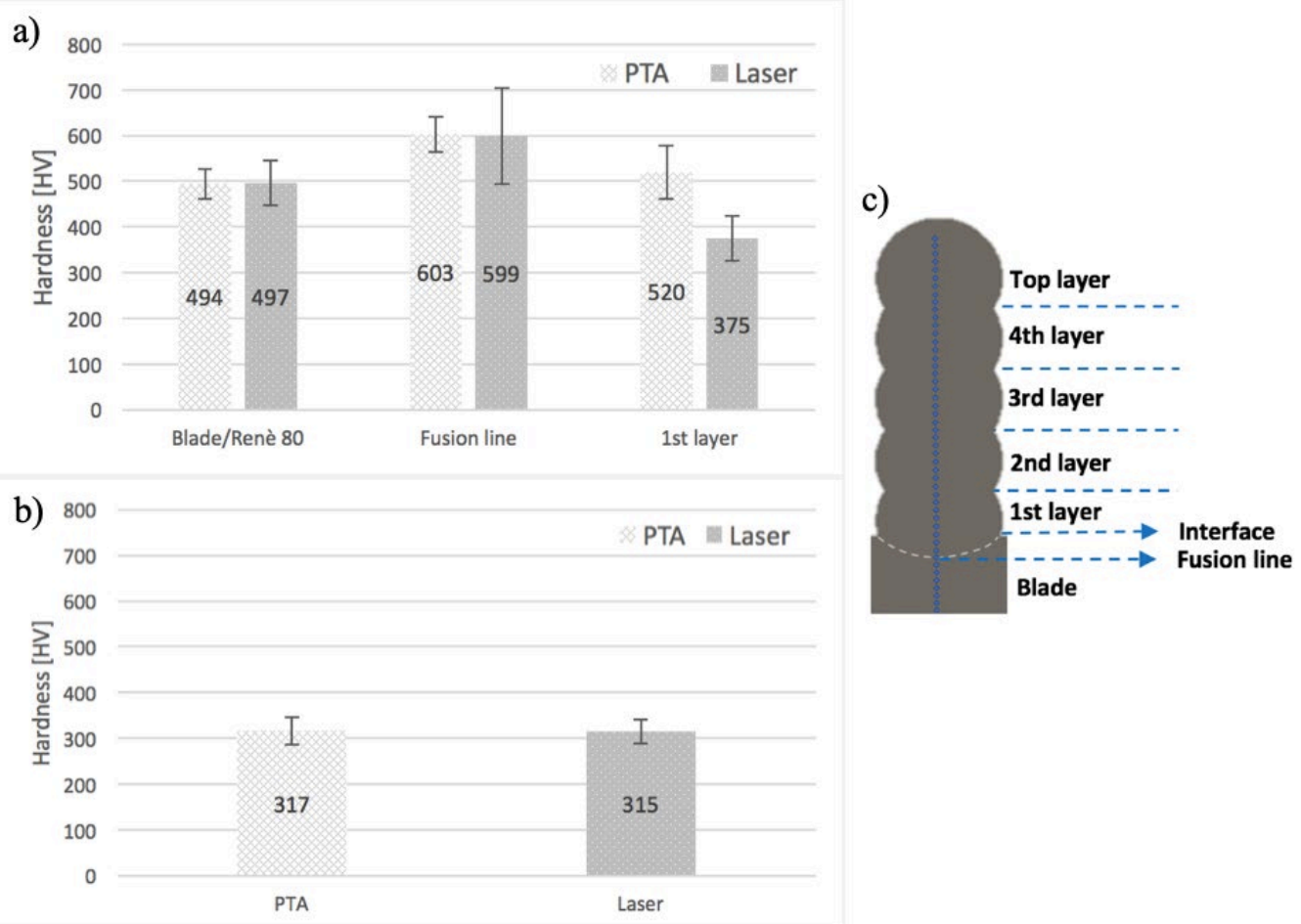

Figure 2. Average hardness across interface between the Renè 80 substrate and deposited layers (a); hardness in the top layers processed with both techniques (b); schematic representation of a hardness profile (c).

A better understanding was gained considering that if IN 625 is contaminated with alloying elements it can undergo age hardening. Age hardening involves solubilization and precipitation of second phases when exposed to a thermal cycle. The diffusion of elements from the René 80 part, such as $\mathrm{Al}$ and $\mathrm{Ti}$, are expected to contribute to the formation of precipitates, even 
gamma prime depending on the amount of these elements. In additive processes the first deposited layers undergo multiple thermal cycles of different intensities depending on the deposition process and the number of layers being processed [15]. The higher heat input of PTA-AM compared to the DLD process causes a higher interaction with the substrate and, as a consequence, a more saturated solid solution forms. The multiple heat cycles imposed by the deposition of subsequent layers causes solubilization and hardening in the first layer accounting for the higher hardness measured after PTA processing. In contrast, the high power density of the DLD concentrates the effects of heat cycles during multilayer deposition, reducing the effects of ageing and also explaining the lower hardness measured following DLD deposition, Figure 2(a).

Both multilayers show a solidification structure with dendrites of a Ni based solid solution and inter-dendritic region containing second phase particles and with very fine porosity. The finer the dendritic structure the finer the second phase particles in interdentritic regions. Also, solid solution saturation occurs due to the imposed cooling rate hence the multiple thermal cycles of AM processing and PDHT will impact differently on the microstructure depending on the deposition technique used. Also, the interaction with the worn parts strongly depends on the additive process and also impacts on the solidification microstructure particularly in the first deposited layers. Figure 3 highlights the microstructure and $\mathrm{Nb}$ composition map of the first and top layers for both processes. It is of relevance to point out that the top layer is in the as-deposited condition whereas the first deposited layer was exposed to a sequence of thermal cycles as each successive layer was deposited. A coarser structure is observed following PTA-AM, associated with the lower nucleation rate and also the lower temperature gradient involved.

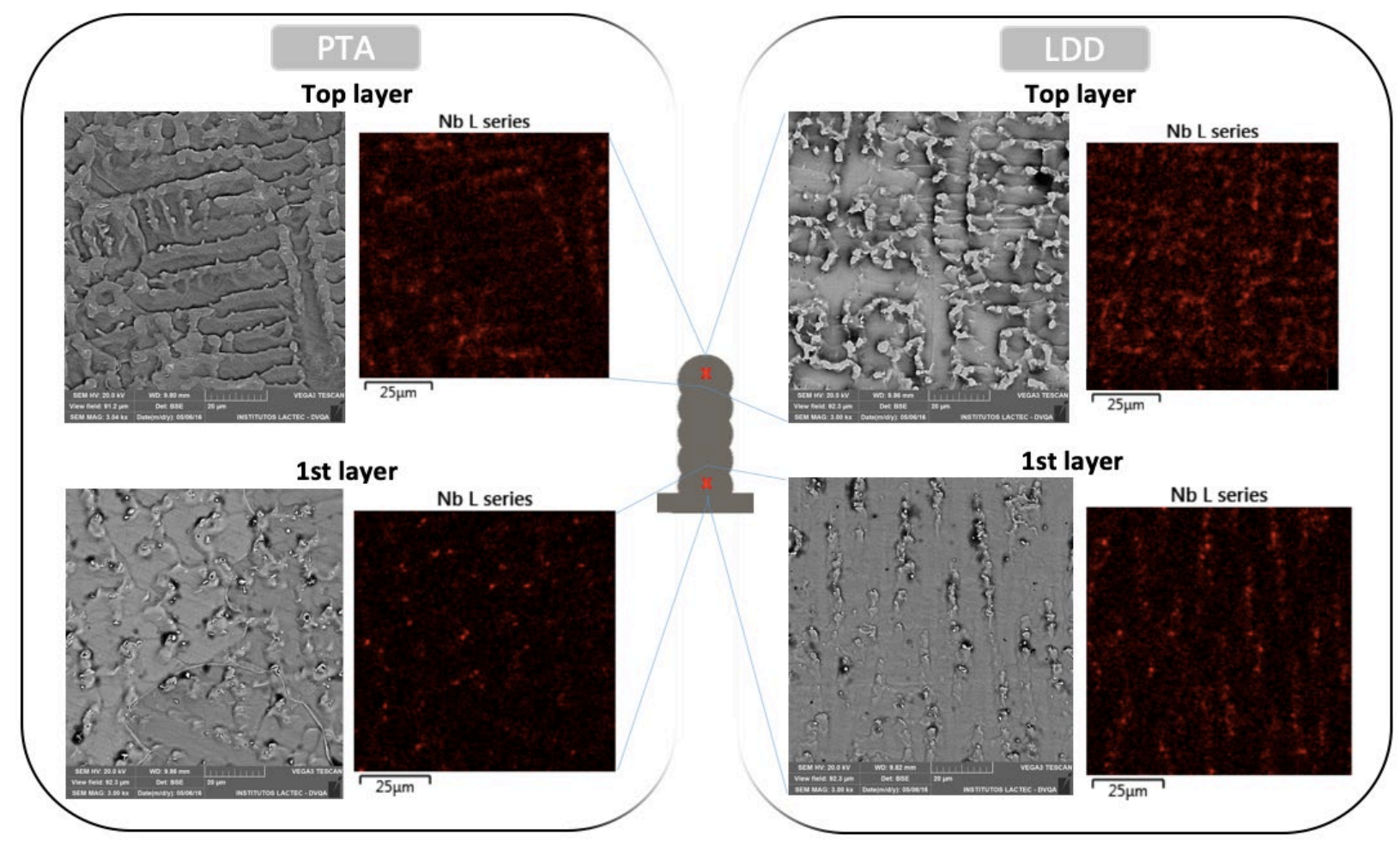

Figure 3. Microstructure (BSE) and Nb chemical composition map of the first and top layers processed with PTA-AM and DLD.

According to Petrzak et al. [16], in nickel alloys elements such as $\mathrm{Nb}, \mathrm{Si}, \mathrm{Mo}$ and $\mathrm{C}$ are segregated during solidification remaining in the melt pool. As solidification advances the melt pool becomes richer in these elements until the interdendritic regions solidify with a higher concentration of alloying elements. Using $\mathrm{Nb}$ to track this behavior, Nb chemical composition mapping of the top layer of both multilayers show a more significant segregation. This structure can be understood based on the lack of thermal history which accounts for the different intensity of aging of the previous deposited layers.

Detailed analysis of the microstructure of the first deposited layer of each multilayer can be made from Figure 4 (a). It suggests an aging response in the initial layers processed with PTA-AM with a larger amount of fine precipitates, in agreement with the higher hardness values measured. It is important to emphasize that it is not appropriate to state any condition as being good or bad because such evaluation will depend on the requirements of each application.

In contrast, Laser processed multilayers, Figure 4(b), did not show such precipitation behavior. This observation strengthens the hypothesis that the high-power density of laser process causes a minor interaction with the substrate and a higher cooling rate that maintains elements mostly in solid solution. 

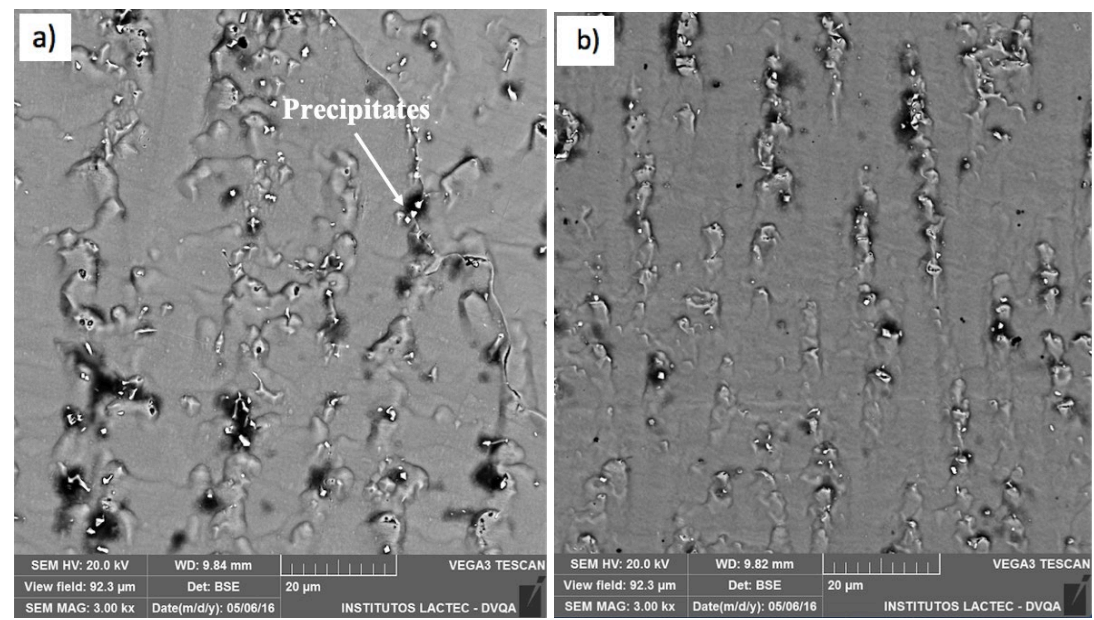

Figure 4. Microstructure (BSE) of the first deposited layer deposited with PTA (a) and DLD (b).

\subsection{Impact of PDHT}

Parts refurbished with additive technologies must undergo a PDHT before use to gain structure homogeneity and stress relief. PDHT enhanced hardness uniformity along the transition between the parts and the recovered area. The multilayers processed with PTA-AM and DLD exhibited a smoother transition between the worn component and the deposited layers. However, a significant impact occurred in the first deposited layers.

The features of each additive processes and the thermal history they impose determine the response of the material to PDHT. Although a more uniform hardness was measured across the interface with the worn substrate each process dictate a specific response from the material, particularly at the first deposited layer. When using PTA-AM, PDHT causes a decrease in the hardness, whereas following deposition with DLD the hardness of the first layer increases, Figure 5(a). The increase in hardness from $375 \pm 50$ to $428 \pm 24 \mathrm{HV}$ of the DLD processing following PDHT can be accounted for by the ageing of the saturated solid solution processed. On the other hand, the decrease from $520 \pm 59$ to $358 \pm 27 \mathrm{HV}$ after PDHT can be associated with an overaged response of the layer processed with PTA-AM whereas the first layer of PTA deposits becomes overaged, leading to a hardness reduction. Hardness of the top layers showed a small decrease with average values of $293 \pm 14 \mathrm{HV}$ and $301 \pm 20 \mathrm{HV}$ for PTA and DLD process respectively as show Figure $5(b)$.

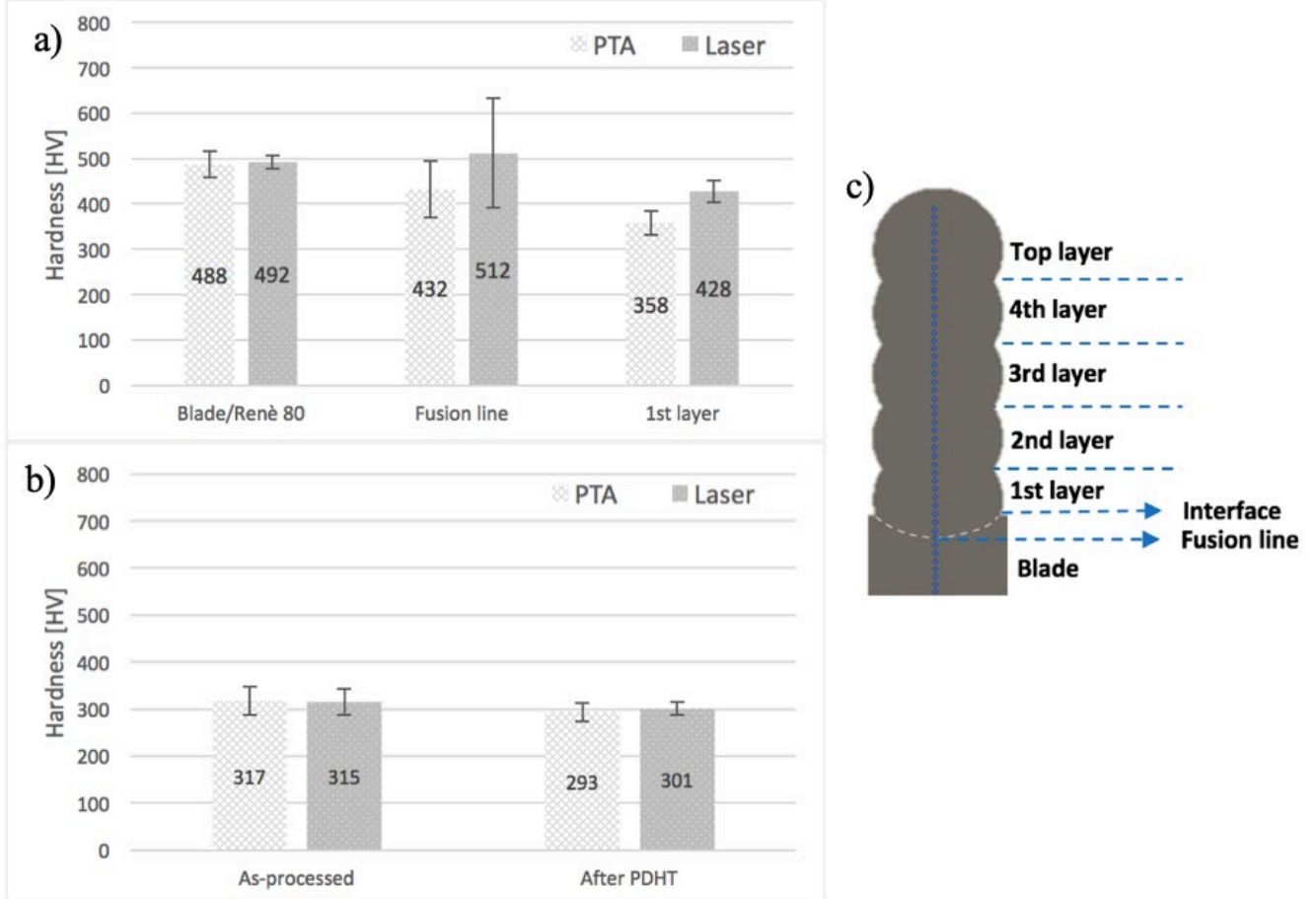

Figure 5. Average hardness across interface between the Renè 80 substrate and deposited layers (a); hardness in the top layers processed with both techniques after PDHT (b); schematic representation of a hardness profile (c). 
A better understanding of the changes in hardness is gain from the analysis of the microstructure, Figure 6. The PDHT did not mitigate the different segregation degrees of multilayers processed with each additive technique. Results shows that, as a general observation, precipitates in PTA-AM are still coarser after PDHT.

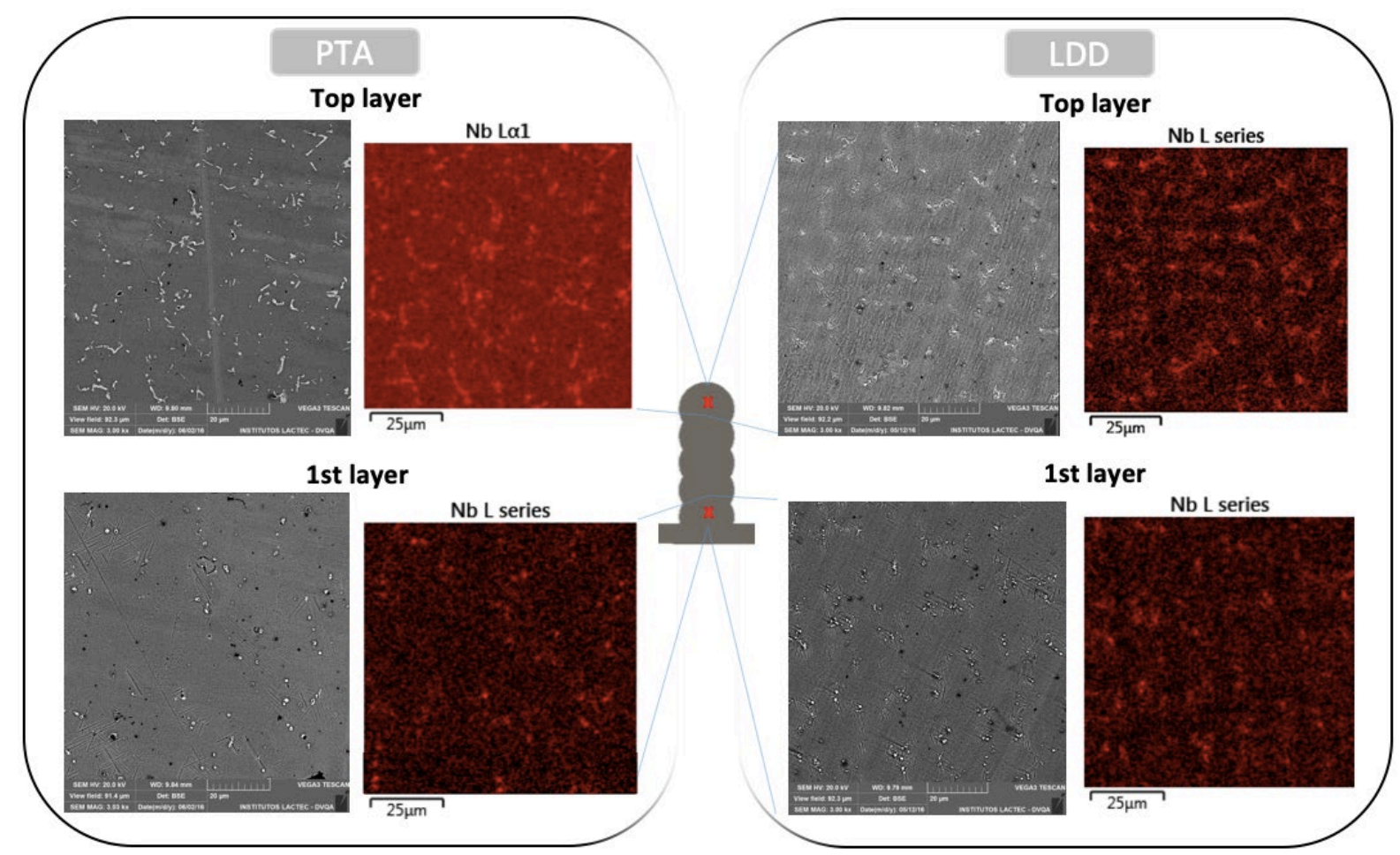

Figure 6. Microstructure (BSE) and niobium composition map of the first and top layers processed with both additive techniques after PDHT.

Correlation between the top and first layers processed by both additive techniques reveals the presence of the acicular $\delta$ phase in the latter. Although present in multilayers processed with both techniques, Laser process resulted in finer precipitates while the PTA process provided coarser precipitates, Figure 7 . The $\delta$ phase formation suggest that, during heat treatment, part of $\mathrm{NbC}$ phase liquidated, resulting in $\mathrm{Nb}$ and Mo rich phase formation [17]. The $\delta$ phase with an incoherent interface with the $\mathrm{\gamma}$-Ni rich matrix and has been associated with a decrease in hardness in multilayer parts processed with wire after heat treatment [6]. Also, is reported that when the $\delta$ phase is formed in large quantities and with high growth, as happens with the multilayer processed with PTA, it may provide a deleterious effect to the properties of the nickel superalloys, compromising the resistance [18] This report is in agreement with measurements that show a reduction in hardness of the multilayers processed with PTA after the PDHT due to the formation and coarsening of the $\delta$ phase. 

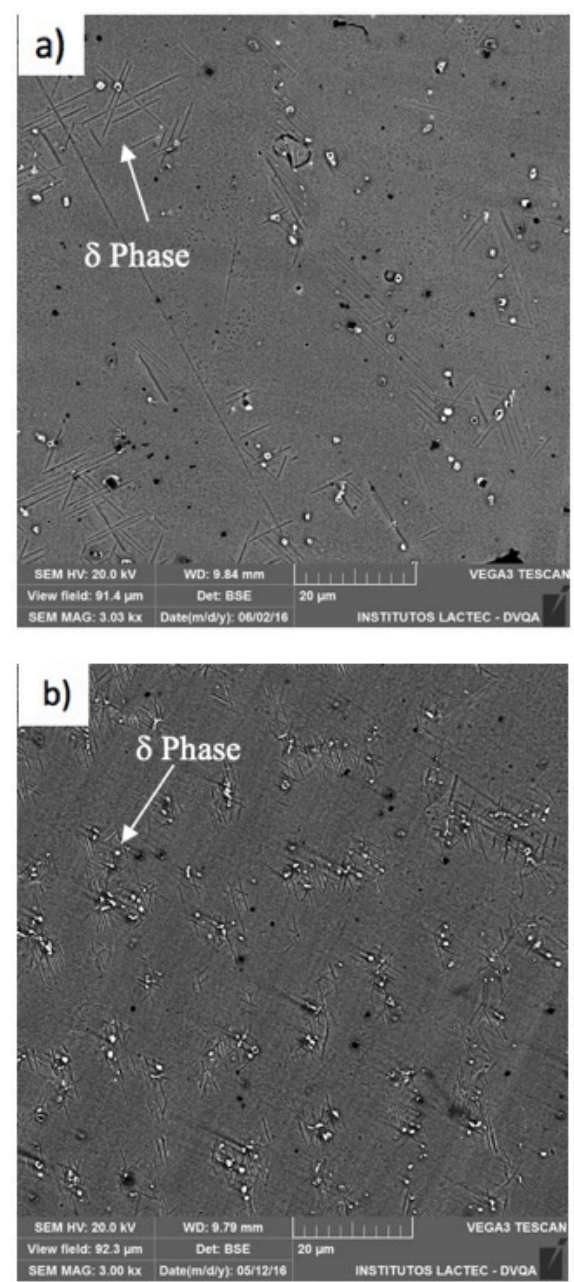
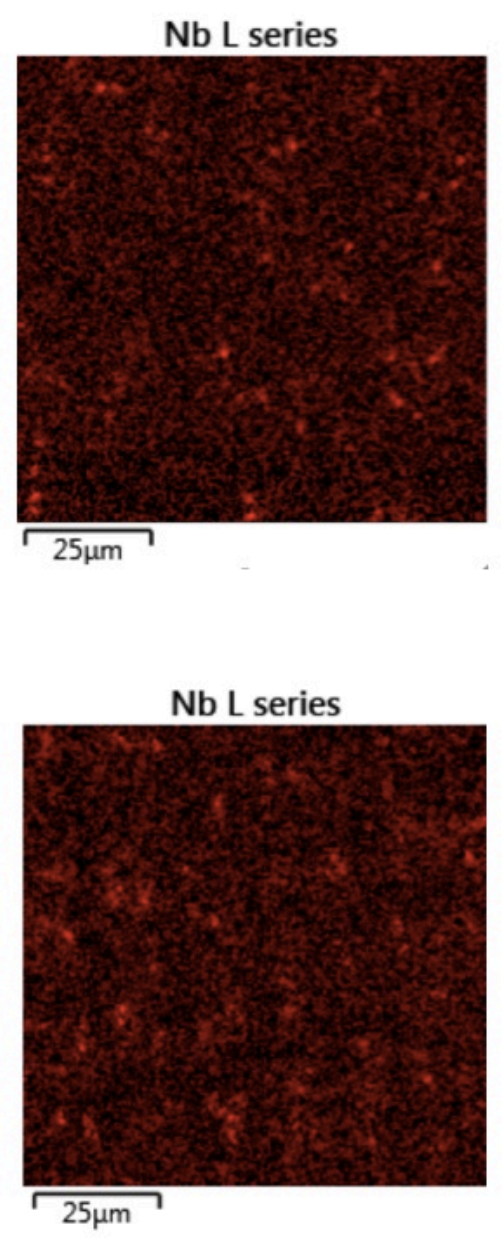

Figure 7. Microstructure and Nb composition map of the first deposited layer processed with PTA-AM (a) and DLD (b) after the PDHT.

The PDHT did not mitigate the texture formed during PTA-AM processing, a clear evidence that the selection of the techniques used to recover the geometry of a worn part impacts on the characteristics of the structure being rebuild. Moreover, the design of components that need maintenance might restrict the selection of techniques available. Large parts with linear features can easily be repaired with arc processes that offer a higher feeding rate whereas small parts with detailed profiles will require techniques with a higher power density that minimizes the impact on the component being repaired.

In between the two scenarios analyzed, there is a wide range of components geometries and sizes for which is mandatory to be acquainted with the features imposed by each additive technology.

\subsection{The impact of feedstock and process choice on multilayers microstructure}

Processing variables should include the feedstock, a condition that alters the effective heat during deposition. Previous work has shown that, compared to wire, deposition with atomized alloys results in more accurate geometries and a better control of microstructure and properties. For a given additive technology, atomized feedstock requires different processing parameters from those used with wire, due to the differences in melting conditions and also due to the different types of interaction with the component being repaired as explained in details in previous study [19].

For the same alloy, IN 625, and the same substrate, Renê 80, the $\delta$ phase distribution and size near the interface with the part being repaired is affected by the processing technique and feedstock Figure 8 . It is observed that deposition with PTA-AM using the atomized alloy (Figure $8(b)$ ) resulted on a $\delta$ phase distribution with characteristics between those observed for the multilayers processed with DLD (Figure 8 (c)) and PTA-AM using IN 625 wire (Figure 8(a)). Moreover, processing with PTA-AM, regardless of the feedstock used, resulted in a texture that is absent in DLD additive processing, Figure 9. Raising the hypothesis that the cooling rate has impacts beyond structure refinement (dendrites and second phase refinement) also affecting texture.

Additive manufacturing is a very attractive technology to refurbish high value worn mechanical parts. However, in order to make additive procedures competitive it is of importance to make available data that compares additives techniques, including the effects of the feedstock. Although out of the focus of the present study, the control of residual stresses also has to 
be addressed for components undergoing maintenance using additive techniques. Residual stresses depend on the solidification rate, which is a consequence of the selected technique, and also the geometry of the component recovered.
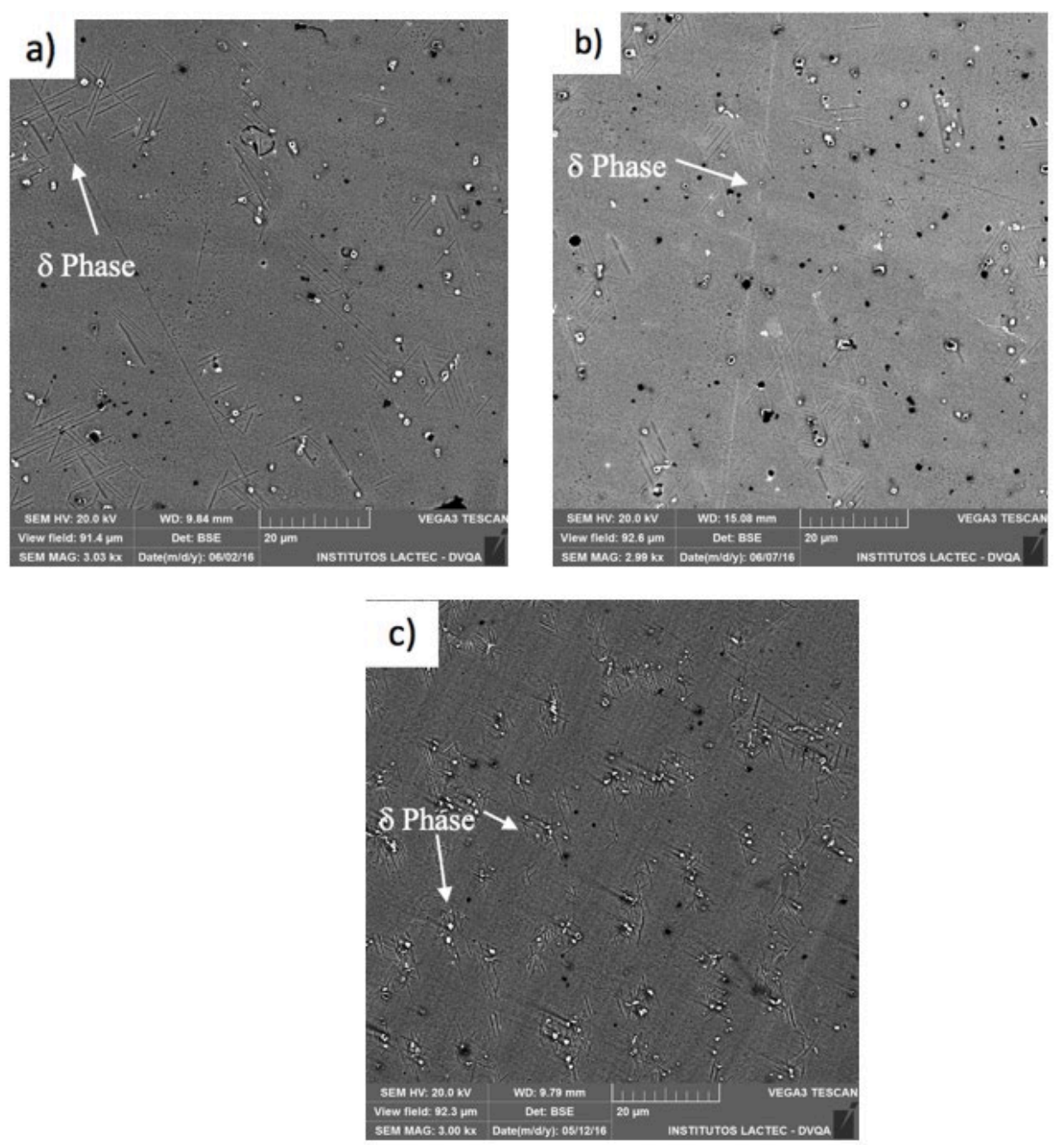

Figure 8. Microstructure (BSE) of the first deposited layer processed with PTA-AM (a) wire, PTA-AM powder (b) and the DLD wire (c), after the PDHT.

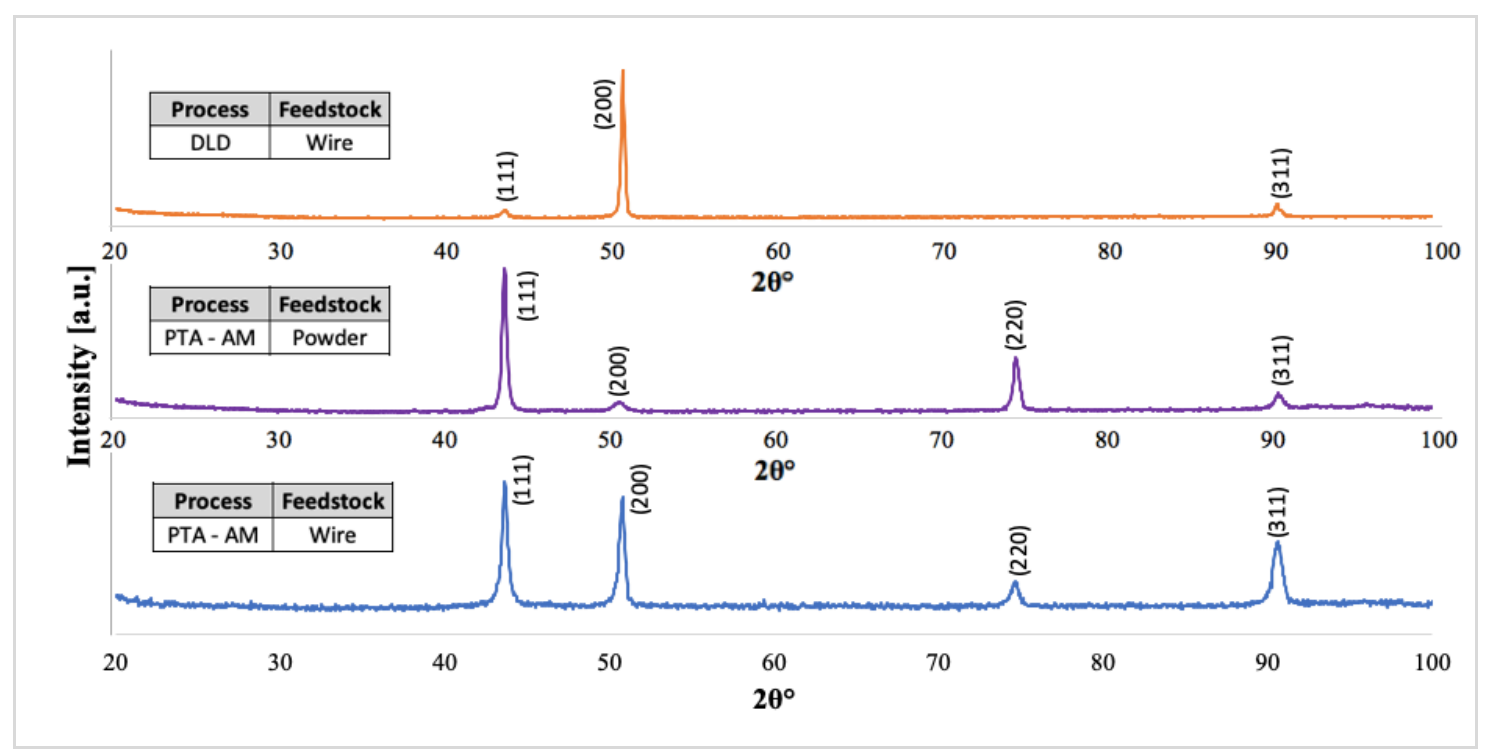

Figure 9-XRD from the top surface of the multilayers after PDHT. 


\section{Conclusions}

In this investigation of the impact of the additive technique in the characteristics of the refurbished area during maintenance of worn parts it is possible to conclude that:

There are differences in the final microstructure of the multilayers deposited as a consequence of the selected parameters for each additive technique.

DLD provide finer second phase particles due to the high cooling rate, consequence of the high-power density offered by this process.

The interaction with the worn part is more significant when selecting PTA-AM processing causing higher dilution and coarser microstructures. Furthermore, the productivity is higher as shown by the larger effective area deposited.

Post-deposition heat treatment enhanced the microstructure and hardness uniformity along both multilayers. However, at the interface with the part being refurbished, PTA-AM layers exhibited overaging accompanied by a reduction in hardness. The saturated microstructure of DLD multilayers undergoes aging during PDHT.

Regardless of the additive technique used, PDHT caused precipitation of $\delta$ phase in layers at the interface with the worn part. Differences in size and distribution occurred depending on the segregation induced by each technique during deposition.

The maintenance of each worn part should include a preliminary study to assess the best additive technique and processing parameters, including the selection of feedstock. The use of powder instead of wire offers a competitive route to enhance features of arc refurbished parts.

\section{Acknowledgement}

Thanks are due Institutos Lactec for the collaboration and for CAPES and CNPQ for the incentive and financial support.

\section{References}

[1] Frazier WE. Metal additive manufacturing: a review. Journal of Materials Engineering and Performance. 2014;23(6):1917-1928. http://dx.doi.org/10.1007/s11665-014-0958-z.

[2] DebRoy T, Wei H, Zuback J, Mukherjee T, Elmer JW, Milewski JO, et al. Additive manufacturing of metallic components - process, structure and properties. Progress in Materials Science. 2018;92:112-224. http://dx.doi.org/10.1016/j.pmatsci.2017.10.001.

[3] Singh H, Jain PK. Past, present and future - the characterization of surface of topography of plasma transferred arc coating. In: Proceedings of the Indian Conference on Applied Mechanics; Jul 2015; Delhi, India. Delhi: Indian Institute of Technology Delhi; 2015. p. 321-326.

[4] Sames WJ, List FA, Pannala S, Dehoff RR, Babu SS. The metallurgy and processing science of metal additive manufacturing. Journal International Materials Reviews. 2016;61(5):315-360. http://dx.doi.org/10.1080/09506608.2015.1116649.

[5] Reis RP, Scotti A. Fundamentos e prática da soldagem a plasma. São Paulo: Artliber; 2007.

[6] Dinda GP, Dasgupta AK, Mazumder J. Laser aided direct metal deposition of Inconel 625 superalloy: Microstructural evolution and thermal stability. Materials Science and Engineering A. 2009;509(1-2):98-104. http://dx.doi.org/10.1016/j.msea.2009.01.009.

[7] Paul CP, Ganesh P, Mishra SK, Bhargava P, Negi J, Nath AK. Investigating laser rapid manufacturing for Inconel-625 components. Optics \& Laser Technology. 2007;39(4):800-805. http://dx.doi.org/10.1016/j.optlastec.2006.01.008.

[8] Special Metals. Inconel ${ }^{\circledR}$ [online]. Huntington: Special Metals PCC Company; 2013 [access 13 aug. 2013]. Available from: http://www.specialmetals.com/assets/smc/documents/alloys/inconel/inconel-alloy-625.pdf

[9] Bhargava P, Paul CP, Premsingh CH, Mishra SK, Kumar A, Nagpure DC, et al. Tandem rapid manufacturing of Inconel-625 using laser assisted and plasma transferred arc depositions. Advances in Manufacturing. 2013;1(4):305-313. http://dx.doi.org/10.1007/s40436013-0044-z.

[10] Xu FJ, Lv YH, Xu BS, Liu YX, Shu FY, He P. Effect of deposition strategy on the microstructure and mechanical properties of Inconel 625 supealloy fabricated by pulsed plasma arc deposition. Materials \& Design. 2013;45:446-455. http://dx.doi.org/10.1016/j.matdes.2012.07.013.

[11] Aghaie-Khafri M, Farahany S. Creep life prediction of thermally exposed rene 80 superalloy. Journal of Materials Engineering and Performance. 2010;19(7):1065-1070. http://dx.doi.org/10.1007/s11665-009-9584-6.

[12] Special Metals. Inconel ${ }^{\circledR}$ alloy 625. Huntington: Special Metals PCC Company; 2013.

[13] Xu F, Lv Y, Liu Y, Xu B, He P. Effect of heat treatment on microstructure and mechanical properties of Inconel 625 alloy fabricated by pulsed plasma arc deposition. Physics Procedia. 2013;50:48-54. http://dx.doi.org/10.1016/j.phpro.2013.11.010.

[14] Mostafa A, Picazo Rubio I, Brailovski V, Jahazi M, Medraj M. Structure, texture and phases in 3D printed IN718 alloy subjected to homogenization and HIP treatments. Metals. 2017;7(6):196. http://dx.doi.org/10.3390/met7060196. 
[15] Xu X, Ding J, Ganguly S, Diao C, Williams S. Oxide accumulation effects on wire + arc layer-by-layer additive manufacture process. Journal of Materials Processing Technology. 2018;252:739-750. http://dx.doi.org/10.1016/j.jmatprotec.2017.10.030.

[16] Petrzak P, Kowalski K, Blicharski M. Analysis of phase transformations in Inconel 625 alloy during annealing. Acta Physica Polonica A. 2016;130(4):1041-1044. http://dx.doi.org/10.12693/APhysPolA.130.1041.

[17] Floreen S, Fuchs EG, Yang WJ. The metallurgy of Alloy 625. New York: Superalloys; 1994.

[18] Dupont JN, Lippold JC, Kiser SD. Welding metallurgy and weldability of nickel-base alloys. New Jersey: John Wiley \& Sons; 2009. http://dx.doi.org/10.1002/9780470500262.

[19] Cardozo EP, Ríos S, Ganguly S, D'Oliveira ASCM. Assessment of the effect of different forms of Inconel 625 alloy feedstock in Plasma Transferred Arc (PTA) additive manufacturing. The International Journal of Advanced Manufacturing. 2018;98(5-8):1695-1705. http://dx.doi.org/10.1007/s00170-018-2340-z. 